\title{
WOMEN'S HEALTH: MIDDLE CLASS HOME MAKERS-VOICES AND CONCERNS IN URBAN BANGALORE CITY
}

\author{
S.P.Srimathi* \\ UGC-Centre for Women's Studies and Department of Women's Studies, NMKRV College, Bangalore, \\ Karnataka, India
}

\begin{abstract}
The slogan "healthy women healthy world' embodies the fact that as custodians of family health, women play a critical role in maintaining health and wellbeing of their families and communities but very little attention is paid to their health care thus leading to wide disparities in access to medical care. Their economic instability, lack of awareness, gendered sex role, high cost of medical expenses, lack of government initiatives, all these plays a crucial role in women not seeking to health care, especially the Home Makers. The paper aims for a health care planning and policies for home maker's health issues by creating awareness among the public, civil and specially women, to ensure that women's health is not addressed merely on biological issue but also as a gender issues. Government role and responsibility and medical practioners and multinational companies to become more responsible stake holders for women's wellbeing. Incorporating the Feminist methodological guidelines the Sampling size will be 1000 urban middle class women in age group 25-60 years varying in their educational qualification, designation and marital status in Bangalore. Descriptive, experiential, exploratory methods, data collection, primary and secondary tools through observation and also interview schedules methods are used. Statistics analyses and Graphical representation of data is incorporated
\end{abstract}

It must be stated that conceptual thought is exclusive to the masculine intellect. Her skull is also smaller than man's and so of course is her brain.

T.Lang 1971 [cited in tavris, 1996:336]

The above quote demonstrates the biological observation [through research] that women are inferior to men. The explosion of feminist research on issues of sex and gender has strongly demonstrated that culture is a greater barrier to equality than biology. Yes there are many more such researches which have necessitated the multiple roles on women's health and wellbeing.

The $21^{\text {st }}$ century has indeed heralded a new chapter in the history of women's health. Right from grass root level organizations to professional medical organizers and practioners have inched a new wave health movement. The lacunae in the research and the movement are in not considering the home makers who have been just benefactors to health on papers.

Since independence, India has witnessed a rapid growth in health industry. The advanced technology in health industry has made a significant contribution in accessibility of health among all class of community. As we all know there have been many private and government sectors in medical field booming to a large extent. The government has indeed made headway in contributing easy access to health services for the underprivileged sections of the society especially women as they have their own health issues that deserve special considerations 
through various policies and initiated programmes. It is indeed a laudable effort on the part of the government .the PHC [ Primary health care centres] and CHC [ community health care centres] act as a catalyst for the health benefits to the underprivileged women of the society. We also see the cream of the society, the working class women through their economic stability is more conscious and keen on health benefits in utilizing them. The hour of question which arises is the middle class home makers who are not the benefactors in any of these health concerns and their voices for survival and existences is least researched. Based on these understanding this study which is a minor research sponsored by the University Grants commission, Government of India seeks to examine with The slogan "healthy women healthy world' embodies the fact that as custodians of family health, women play a critical role in maintaining health and wellbeing of their families and communities but very little attention is paid to their health care thus leading to wide disparities in access to medical care. Their economic instability, lack of awareness, gendered sex role, high cost of medical expenses, lack of government initiatives, all these play a crucial role in women not seeking to health care.

\section{Origin of the research problem}

The emergence of globalization, liberalization has led to the working affluent classes and working middle class women seeking health benefits from the multi corporal health sectors. Whereas the middle class home makers due to their economic dependency on family members fail to have access to any of the health benefits of the multi corporal health sectors.

\section{Interdisciplinary relevance}

This research would have more validity when health issues are addressed not only from physiological but also psychological perspective. As it is a known fact women hardly discuss about their ailments due to various sociocultural constraints even if so the applicability is only to physical ailments rather than psychological. We also have to note here it was Betty Freidan's book on 'Feminine Mystique' which highlighted the psychological symptoms and problems American women goes through, which necessitated the importance.

\section{Review of the research}

Books like Boston Women's Health: Our bodies Ourselves and Elizebth A. Rider's Psychology of Women: Our Voices address women's health both from psychological studies as well as physiological in western and European countries. As Women's Studies have yet to successfully establish its territorial existence in India, the research on women's issues in the country is also at a slow pace. There have been many published books, articles and journal on women's diet and nutritional intake. Reconfiguring Reproduction: Feminist Health Perspectives on Assisted Reproductive Technologies [2014edited by Sarojini .N, Vrindha Marciah] address reproductive technology and women's rights in global context. Women's Health and Nutrition: Role of State and Voluntary organisation- [2017 ArpitaVerma] highlights the health and nutritional status of Women in rural India. Research data on women and mental health under Indian journal of Psychiatry and National Institute of Mental Health has various write ups on symptoms and the treatment. The lacunae in the mentioned books and journalism the lack of research inputs in particular to middle class home makers as they are silent sufferers to many physical and psychological ailments and the fact of not disclosing to family members because of their economic, social and psychological dependency on family members. The article on Let's Talk the Invisible Pain of Home Makers [https://www.huffingtonpost.in/epsyclinic/lets-talk-about-the-invisible-pain-of-homemakersthis-world-hea_a_22023640/]specifically has a small write up on the issues. Not until when researchers use feminist techniques, tools, methods or guidelines will women become subjects of their own history - the practise and belief of which, I as a researcher would modulate my paper on. 


\section{Significance of the study}

The study would play an important role in creating awareness among the public, society, civil and specially women on the health issues. The research would also highlight the role of the government, medical practioners, and multinational companies to become more responsible and stake holders for women's wellbeing. As the slogan "healthy women healthy world' would create a balanced life style, healthy family life, and also reduce the gender disparity in medical system.

\section{Objectives}

To strengthen the study with the application of feminist research methodology

To aim for a comprehensive health care planning and policies for middle class home makers health issues

To ensure that middle class women's health is not addressed merely on biological issue but also as psychological

To facilitate for middle class women's wellness and well being

\section{Methodology}

There has been ample of studies and analysis on women's health It is a known fact that there are not much studies and research on the new emerging issues within women's health and there needs to be an effort in understanding and explaining the nature of women's experience which can be used as an interim guide to explore the new issues Women's health: home makers-voices and concerns. By and large many of the research on women's health see merely the physical wellbeing not the mental and emotional aspects of health concerns

As there is lack of awareness and consciousness on identifying women's experience from a feminist perspective, we need to adopt both theoretical perspective and feminist methodological guidelines to address the issue

Application of feminist research methodology and as a feminist I firmly believe in subjectivity application , Traditional science embraces the values of objectivity where the observer and the observed are separate and it believes in expertise, neutrality, separateness becomes an important part of true objectivity whereas the feminist scholars reveals that the observer and the observed are not separated. They believe in subjective knowledge, understanding, communication and experience. Conscious subjectivity involves the consciousness among the researchers and the research. The subjective experience of each of the researched woman is validated and acknowledged as Marcia Westcott suggests inter subjectivity where woman are at the centre of the study and they are neither compared nor measured against normative male standards where research of woman would become research for woman only if the researchers own experience are counted and the theory and the practice of a woman is split. In a battered women cases if conscious subjectivity or inter subjectivity is applied in the research, even though the researcher may not have been battered in this society they would have experienced some forms of humiliation and survived. It is in this context the conscious subjectivity and inter subjectivity becomes relevant.

The sampling size is 1000 home makers from the urban middle class women in Bangalore and the sampling would also be random which consists of females ranging from the age group of 25-60 years. The sample would be literate population from urban areas but varying in their educational qualification, designation and marital status. 
The study would be a combination of descriptive experiential, exploratory methods. Data collection would have both primary and secondary tools through observation and also interview schedules. Statistics would be used to analyse the data to provide a clear insight into the issue. For this purpose percentage analysis will be carried out. Graphical representation of data will also be used to improve the effectiveness of presenting the data.

The questionnaire is not based on any assumptions; it is based on subjectivity and personal experiences of interacting with women in their every walk of life and them sharing their health related problems.

The questionnaire was framed in a way where there is a sense of self - actualization and creating an awareness to know their rights.

The questionnaire was prepared with both open ended and closed ended questions.

The analysis is divided into two sections: Personal and Family Responsibilities, Health expenses and Government initiatives.

I. In personal and family responsibilities the overall analysis results were based on Gendered thinking among men and women in the family and also where psychological issues are not considered as health issues. The gendered stereotyped roles are persistent in families with a subtle existence which may look a minuscule for anyone to relate it to health issues. There were many such dialogues and discussion between the respondents and the interviewer. At times as an interviewer based on experiential analysis I had to sensitize on gender disparity in families especially related to health issues and create a platform for the respondents to respond. This was a challenge to me as well as an exhilarating experience. It is usually assumed by women [51\%] in a family that men and children's health priority needs to be given more importance.

Gendered thinking among the family members.

\begin{tabular}{|l|l|l|}
\hline category & Issues & Percentage \\
\hline 1 & Gendered thinking in the family & $51 \%$ yes \\
\hline 2 & men are also insensitive to women's health issues in the family & $57 \%$ agreed \\
\hline 3 and 4 & $\begin{array}{l}\text { How much of attention is given to your health issues in your family? Partial } \\
\text { involvement and full involvement }\end{array}$ & $\begin{array}{l}\text { Partial involvement } \\
-53 \%, \text { and full } \\
\text { involvement }-46 \%\end{array}$ \\
\hline 5 & Women discussing their health with the family & $92 \%$ said no \\
\hline
\end{tabular}




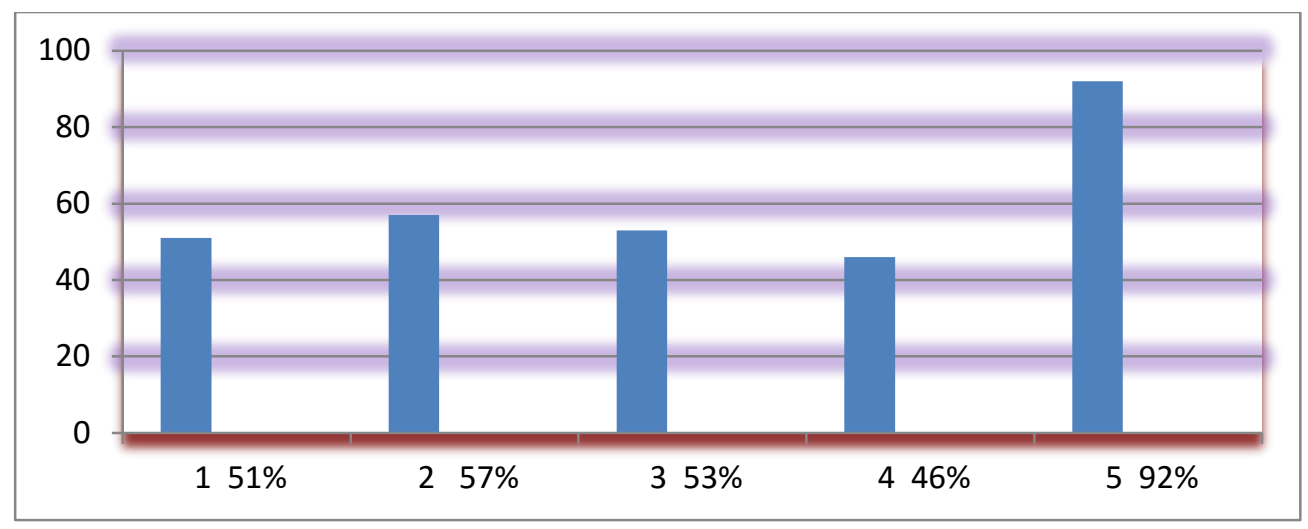

Figure 1 Gendered thinking among the family members

. 53\% respondents opined that the role of family members in women's health issue was for a partial involvement. This is in reference to family members showing the concern to health issues but inability to be a part of woman's struggle as most of the family feel it's a woman's destiny that she has to undergo these struggles like any other woman. Men [57\%] are also insensitive to women's health issues, by not accompanying them to their hospital visits, not helping in household chores, lack of emotional support. $46 \%$ of the respondents felt their family paid full attention to their health concerns. The respondents were not clear enough to what exactly is full attention, family showing the concern to taking the responsibility of nurturing the women during her ailments were not much focused by the respondents. The reasons could also be where $92 \%$ of women do not share their health issues with the family. The socialization pattern in the women bearing the pain and sufferings silently are considered "virtuous women". Lots of women are too sensitive to talk about their sexuality and it is considered as a taboo not to openly discuss these issues in the family.

Importance of health issues under various categories

\begin{tabular}{|l|l|l|}
\hline Category & Issues & Percentage \\
\hline 1 & General health check up & $66 \%$ \\
\hline 2 & Gynaecological & $26 \%$ \\
\hline 3 & Psychological & $8 \%$ \\
\hline
\end{tabular}

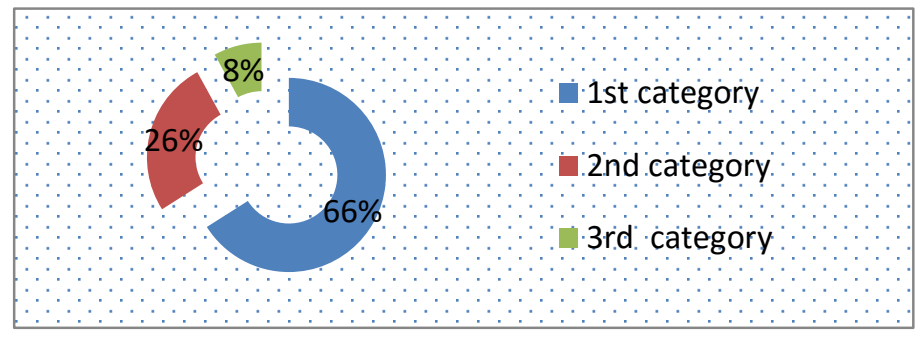

Figure 2 Importance of health issues under various categories.

The third aspect identified as psychological issues [ $8 \%$ ]is not considered as health issue. 66\% of the respondents consider general symptoms like cold, fever, headaches, as health issues and this applies to their health check-up, anything related to Gynaecological its only $26 \%$., This shows the apathy towards psychological issues among women. Women's mental health is simply understood as an emotional outburst. It is under diagnosed and written off as a result of hormonal issues or genetic differences. 
Do they experience loneliness, depressions and insecurity during the following categories?

\begin{tabular}{|l|l|l|l|}
\hline Category 1 & Category 2 & Category 3 & Category 4 \\
\hline Menopause $-43 \%$ yes & Menstrual cycle- $19 \%$ yes & Middle age crisis $-15 \%$ yes & Domestic violence - 23\% yes \\
\hline
\end{tabular}

Failing to identify the psychological ailments within themselves, the respondents were further questioned on do they experience loneliness, depressions and insecurity and to identify the areas. As per to their response during Menopause [43\% ] ,Menstrual cycle [19\% ] Middle age crisis- [15\% ] ,Domestic violence [23\%.]These opinions once again give a dark side of psychological interventions where only biological factors take precedence over social factors. Home makers perform multitask work without any reward and appreciation from the family which leads to low self-esteem. There could be instances where a home maker due to family pressure, obligation or economic dependence on family may not rightfully claim to be what they want in their lives. As Betty Friedan rightly points out in her writing Feminine Mystique women going through the "problem that has no name' and 'a crisis in women's identity' has an inner voice within themselves that says I want something more than my husband, my children, and my Home. Based on experiential analysis and subjectivity methods during the interview sessions the above explanations very clearly indicated that the respondents were not aware of the social factors like low self-esteem, identity crisis. They were also unaware that these factors could also lead to mental health problems. The above analysis vouches for an immediate intervention of feminist psychology in sensitizing and creating awareness to women on mental health issues.

\section{Health expenses and government initiatives}

Reasons for women to neglect their health

\begin{tabular}{|l|l|l|}
\hline Category & Issues & Percentage \\
\hline 1 & $\begin{array}{l}\text { Do Working women have more liberty to spend } \\
\text { on hospital expenses than home makers }\end{array}$ & $69 \%$ yes \\
\hline 2 & High cost of medical expenses & $49 \%$ yes \\
\hline 3 & dependent on family members for hospital visits & $66 \%$ yes \\
\hline 4 & Lack of knowledge on medical terminologies & $19 \%$ yes \\
\hline 5 & $\begin{array}{l}\text { Do not get updated on any latest medical } \\
\text { interventions. }\end{array}$ & $50 \%$ yes \\
\hline 6 & visit hospital only on need basis & $83 \%$ yes \\
\hline
\end{tabular}

The reasons for women neglecting their health are also due to the fact of high cost of medical expenses and lack of government initiatives. Most of the home makers [69\%] feel working women have an ability to spend on their health ailments and they are capable of taking the decisions independently. The other factors like high cost of medical expenses [49\%], [66\% ]respondents dependent on family members for hospital visits,[19\%,] lack of knowledge on medical terminologies , [50\%] of the respondents do not get updated themselves on health issues due to lack of understanding the medical interventions, [83\%] of the respondents visit hospitals only on necessity. There is no periodic checkup of their health on regular base.

India is witnessing a global health care movement and is expected to rank amongst the top three healthcare markets by 2020 . Private health care accounts to $74 \%$ of the country's total health care expenditure. Healthcare sector as fastest growing industries private sectors comprises $80 \%$ of total India's hospital industry. Some key players are Appollo, CARE, Fortis, Manipal, Narayana Health Care. The low cost of medical services compared to developed countries has resulted in a rise in the country's medical tourism of well-educated English speaking medical staff in the state of the art private hospitals and diagnostic centers. The Rising income levels, ageing 
population, growing health awareness and changing attitude towards preventive healthcare is expected to boost healthcare services demand in future. Moreover, India has emerged as a hub for R\& D activities for international players due to its relatively low cost of clinical research and Conducive policies for encouraging FDI, tax benefits, favorable government policies coupled with promising growth prospects. It has helped the industry to attract private equity, venture capitals and foreign players [ health care IBEF www.ibef.org]

The above illustrations clearly show the disparities for working women and middle class home maker's access to health initiatives. A working woman has more access to health benefits and insurances, knowledge and updates on latest health initiatives; she could be able to converse easily with the medical staff in comparatively to middle class home makers. Middle class home maker lack of economic stability depends on medical expenses to be borne by the families pocket than through insurance.

\section{Government initiatives}

$88 \%$ respondents felt government should initiate more health facilities for middle class home makers. [34\%] home makers opined government should provide low cost medicines this could help the middle class home makers to buy the medicines in time, $14 \%$ wanted the health awareness camps and $20 \%$ wanted more informative on periodical checkups. [20\%] felt easy availability of doctors would help them in betterment of health.
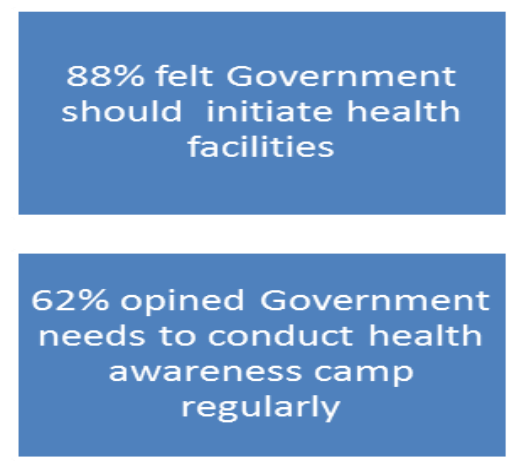
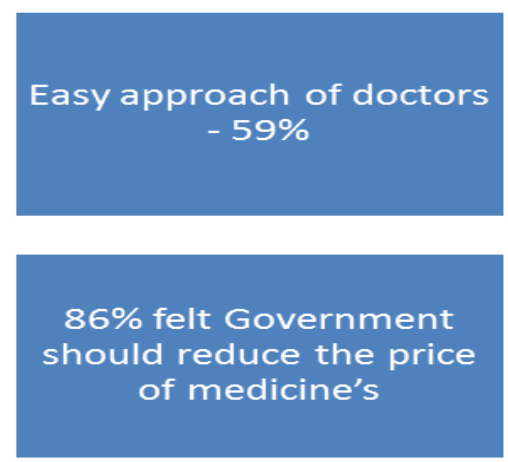

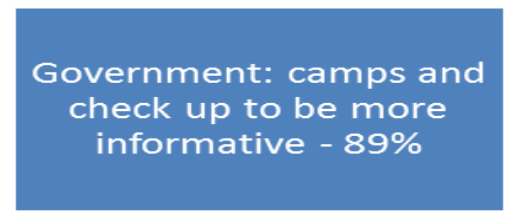

$83 \%$ of the respondents felt government should bear the hospitals expenses and allocate a separate budget. The respondents found it difficult to comprehend the meaning and existence of counseling the meaning and existence of counseling centers and all women clinics. With a detailed explanation to roles and responsibilities, the respondents felt these types of centers and clinic would make them more comfortable and benefit them to have access for better health facilities. 


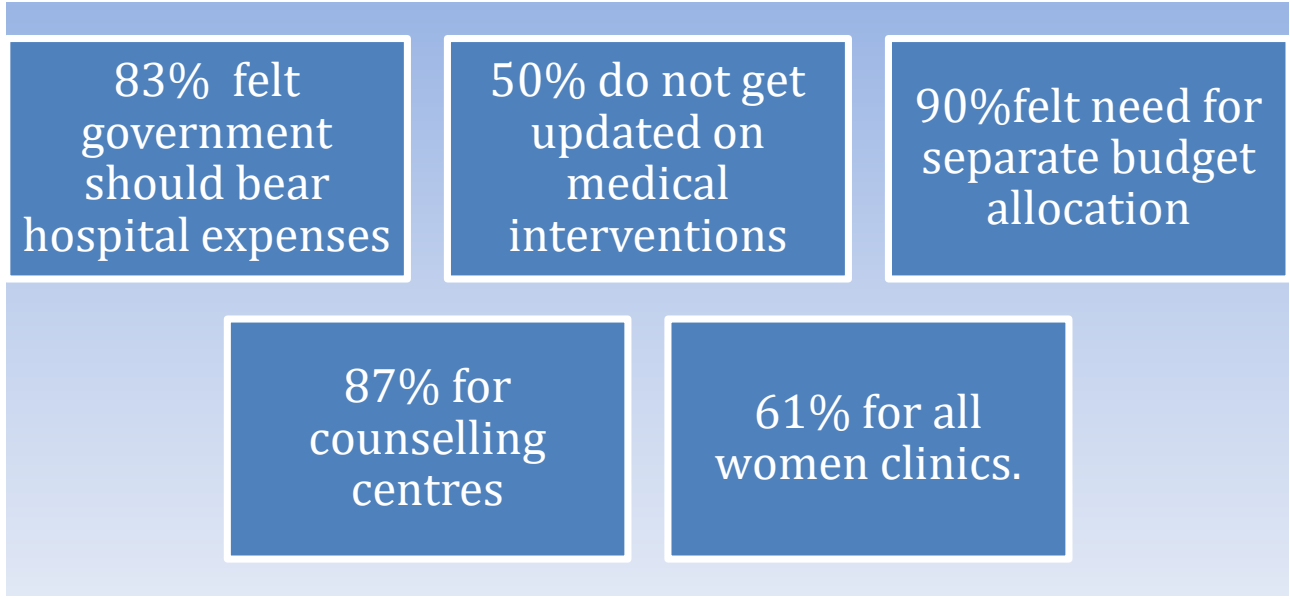

\section{Recommendations}

- Prominence to mental health issues

- The onus is on the government to establish well-structured health benefits through policies and programmes for the middle class home makers

- Inclusion of women [especially homemakers] in medical research

- Sufficiently exploring more health issues of homemakers

- Gender biased care system should be addressed [health professionals interacting with women and men]

- Male physicians need to establish more interpersonal rapport with their patients and provide them with information

- Multinational companies should give the prescription of drugs effects especially in reproductive health.

- Counselling centres to function 24/7. Equipped with full-fledged infrastructure

\section{Conclusion}

As a part of feminist research methodology and as an interviewer I wanted to get the pulse of the respondent on the survey with no questions attached to it but just opinion, where $60 \%$ felt the survey to be both informative and sensitizing. Few respondents felt that they became more aware of their rights. The discussion and the experiential method adopted by the interviewer gave an insight into how one can become a survivor to a gendered socialization process.

The respondents have clearly expressed in the survey a need for comprehensive Government initiatives like medical benefits for the middle class home maker. In the budget allocation State government or the Central government has to bring out specific health related policies and programmes for the middle class home makers. The Government has initiated few health policies and programmes in general like recently introducing the world's largest health insurance scheme for India's 50 crore poor population under the universal health care through national health protection scheme which was also in the interest of the poor. There are primary and maternal health care centres in urban and rural India for the marginalised sections of the society.

The above study highlights women being ignorant of the fact mental health is also a health issue and believing biological problems amount to health issues. In India, the burden for depression is $50 \%$ higher for women than it 
is for men. In April 2016, the BBC published a telling report titled "Why Are India's Housewives Killing Themselves?" noting the staggering statistic that 20,000 homemakers killed themselves in 2014, as compared to 5650 farmers. Yet, there was no furore, no media interest. More than any other group in the country, perhaps, it is the housewife who is rendered the most invisible - in life as well as in death. She has no one taking up her cause, no one fighting for her and that one of her "multiple goddess-like hands" is juggling a noose or a vial of poison[https://www.huffingtonpost.in/epsyclinic/lets-talk-about-the-invisible-pain-of-homemakers-this-worldhea_a_22023640/]

Based on the findings this paper could be further developed into a major study focusing and initiating a dialogue on the government's responsibility in bringing out health related policies and programmes, for the well-being of home makers.

\section{References}

Friedan, Betty 1997, the Feminine Mystique ,New York, W.W.Norton paper back

Roberts, Helen,1981[ed] Doing Feminist Research, London : Routledge and Kegan Paul

Verma, Arpita, 2017 Women's health and nutrition: role of state and voluntary organization -RawathPublication , New Delhi

Sarojini N, MarciahRindha -2014 Reconfiguring Reproduction: Feminist Health Perspectives on Assisted Reproduction Technologies

[https://www.huffingtonpost.in/epsyclinic/lets-talk-about-the-invisible-pain-of-homemakers-this-world-

hea_a_22023640/] 